\title{
Media and scientific communication: a case of climate change
}

\author{
MAXWELL T. BOYKOFF \\ Environmental Change Institute, Oxford University Centre for the Environment, \\ Dyson Perrins Building, University of Oxford, South Parks Road, Oxford OX1 3QY, UK \\ (e-mail: maxwell.boykoff@eci.ox.ac.uk)
}

\begin{abstract}
This paper explores how media representational practices shape and affect current international science and policy or practice communications, through a focus on climate change. Many complex factors contribute to these interactions. The norms and pressures that guide journalistic decision-making and shape mass-media coverage of anthropogenic climate science critically shape current discourses at the highly politicized climate science-policy interface. This paper investigates the multifarious journalistic, political, cultural and economic norms that dynamically influence media coverage of climate science. It explores the case-study of climate change to also work through factors shaping the translation of uncertainty in climate science. This project demonstrates that mass-media coverage of climate change is not simply a random amalgam of articles and segments; rather, it is a social relationship between scientists, policy actors and the public that is mediated by such news packages. Moreover, this research shows how mass media play a significant role in shaping the construction and maintenance of discourse on climate change at the interface of science and policy.
\end{abstract}

It can often feel like an insurmountable challenge to effectively communicate environmental geoscience via mass media. To do so, one must compress the complexities of time and spatial scales into succinct yet accurate 'sound bites' as well as crisply worded commentary. These portrayals are what are typically valued by policy actors, mass media and public citizens. Although this process can seem akin to trying to adequately summarize the contours of biogeochemistry in the space of a picture postcard, this is the challenge at hand.

In the spirit of writer John McPhee, science communication can be situated within the larger landscape of this geological time and space that is represented and described. In Annals of the Former World, McPhee provides the well-known analogy that the 4.6 billion year history of time on Earth can be considered like distance from fingertip to fingertip with one's arms spread wide. He writes that, "the Cambrian begins at the wrist ... all of the Cenozoic is in a fingerprint, and in a single stroke with a medium-grained nail file you could eradicate human history' (McPhee 1998).

Thus, perhaps it would merely take a finegrained nail file to remove the history of science communications and mass media. Organized studies of the art of communications, called Rhetoric, began in ancient Greek and Roman times. However, it was not until the 1920s that scholars actually began to speak of such activities as 'media', as they are now widely dubbed in contemporary society (Briggs \& Burke 2005). Since these early roots and through the Middle Ages and
Renaissance, media representations have encompassed a wide range of activities and modes of communication. From performance art, plays and poetry to news and debate, media portrayals have drawn on narratives, arguments, allusions and reports to communicate various themes, information, issues and events. The increasing reach of modern media communications has led to the term 'mass media'. Mass media have played an important role in translation (of information, concepts, developments, debates) between communities, such as science and the public. 'Mass media' are now commonly referred to as the publishers, editors, journalists and others who constitute this communications industry, and who translate information, through production, interpretation and dissemination, through outlets such as newspapers, magazines, television, radio and the Internet. Through human time scales, mass-media coverage has proven to be a key contributor, among a number of factors, that has shaped and affected continuing interactions between science, politics and the public. These media communications unfold within larger contexts that include elements such as regulatory frameworks, technical capacity challenges, cultural and institutional pressures, as well as journalistic norms.

This paper surveys some of these interacting factors in the production of mass-media representations, through this focus on communicating science via mass media. It explores the case-study of climate change to work through political, economic, social, cultural and journalistic pressures, 
and how these influence media 'framings'. The paper then illustrates salient features of these communications through a discussion of factors shaping the translation of uncertainty in climate science. The focus here is on the production of media portrayals and associated factors, and thus does not centrally take up the complex and non-linear connections to public uptake and/or resistance as well as issues of individual (dis)engagement. However, these framing processes provide explicit links to these other arenas. Once news texts, segments and messages (from television or radio broadcasts, to printed newspapers or magazines, and Internet communications) are assembled, they compete in public spaces for attention. Moreover, these public discourses permeate and integrate to varying degrees into personal understanding and behaviour. Precisely how this information is interpreted and translated into decisions and potential behavioural change is complex, dynamic and contested, and feeds back into continuing production processes. Discussing these connected issues in detail is beyond the scope of this contribution.

\section{Communicating (climate) science through mass media}

In recent decades, studies have consistently found that the public garners much of its knowledge about science from the mass media (e.g. Nelkin 1987). In the case of climate change, research has also shown that accurate knowledge of its causes is the strongest predictor of a person's stated intentions to act (Bord et al. 2000). Thus, it is important to consider the role of mass media in current climate science, policy and practice, and examine drivers of as well as effects from these media portrayals. In other words, media representations are an important factor in public understanding and engagement with climate science, and thus deserve critical consideration.

Figure 1 tracks the quantity of 'climate change' or 'global warming' coverage in 40 of the most influential English-language world newspapers since 1987. The sample was compiled by using the Lexis Nexis database, and selecting articles where at least one of these terms appeared in the headline or somewhere in the first three paragraphs. These newspapers cover 17 countries across five continents, and thus provide a proxy for media attention paid to the issue over the last two decades. Media coverage of climate change or global warming increased substantially in Western Europe and North America beginning in 1988. Many factors contributed to this rise in coverage. Among them was a newsworthy speech by UK Prime Minister Margaret Thatcher to the Royal
Society of London, where she spoke out about the threat of climate change, among a host of environmental issues. She asserted, 'we may have unwittingly begun a massive experiment with the system of the planet itself' (Leggett 2001, p. x). Across the Atlantic, NASA scientist James Hansen testified to the US Congress that summer, and said he was '99 percent certain' that warmer temperatures were caused by the burning of fossil fuels and not solely a result of natural variation (Shabecoff 1988, p. A1). This was also an election year in the USA, where the issue of climate change permeated campaign promises, such as George H. W. Bush's vow to 'fight the greenhouse effect with the White House effect' (Peterson 1989, p. A1). Moreover, the summer of 1988 was one marked by extreme drought and high temperatures throughout North America. These concomitant events were thought to sensitize many, including the media community, to the issue. In the science and policy spheres, 1988 was also the year in which the United Nations Environment Program (UNEP) and World Meteorological Organization (WMO) created the Intergovernmental Panel on Climate Change (IPCC), and the WMO held a landmark international conference in Toronto, Canada called 'Our Changing Atmosphere' (Gupta 2001). Coverage increased through 1990, the year in which the IPCC First Assessment Report on climate change was released. In looking into the content of news coverage over these years of ebbs and flows in the quantity of coverage, certain events garnered particular media attention. For instance, the 1992 UN Framework Convention on Climate Change (UN FCCC), the 1997 Kyoto Protocol, and the releases of IPCC Second and Third assessment reports in 1995 and 2001 were covered heavily in Western European and North American media. Coverage in Australia, New Zealand, the Middle East, Asia, Eastern Europe and South Africa remained low overall until 1997, the year in which the Kyoto Protocol was negotiated. At the negotiations in Kyoto, Japan, registrants included 3500 journalists from over 400 media organizations in 160 countries and discussions took place regarding phases of mandatory commitments to reduce greenhouse gas emissions throughout the world (Leggett 2001).

However, the most evident increases in media attention throughout all the regions came in 2005 and 2006. Again, through examinations of the content of these news articles it is evident that specific single as well as linked events contributed to this. For instance, in 2005 the Group of Eight (G8) Summit in Gleneagles, Scotland attracted media attention, as climate change was one of the key items on the policy agenda. Moreover, Hurricane Katrina, which made landfall in August 


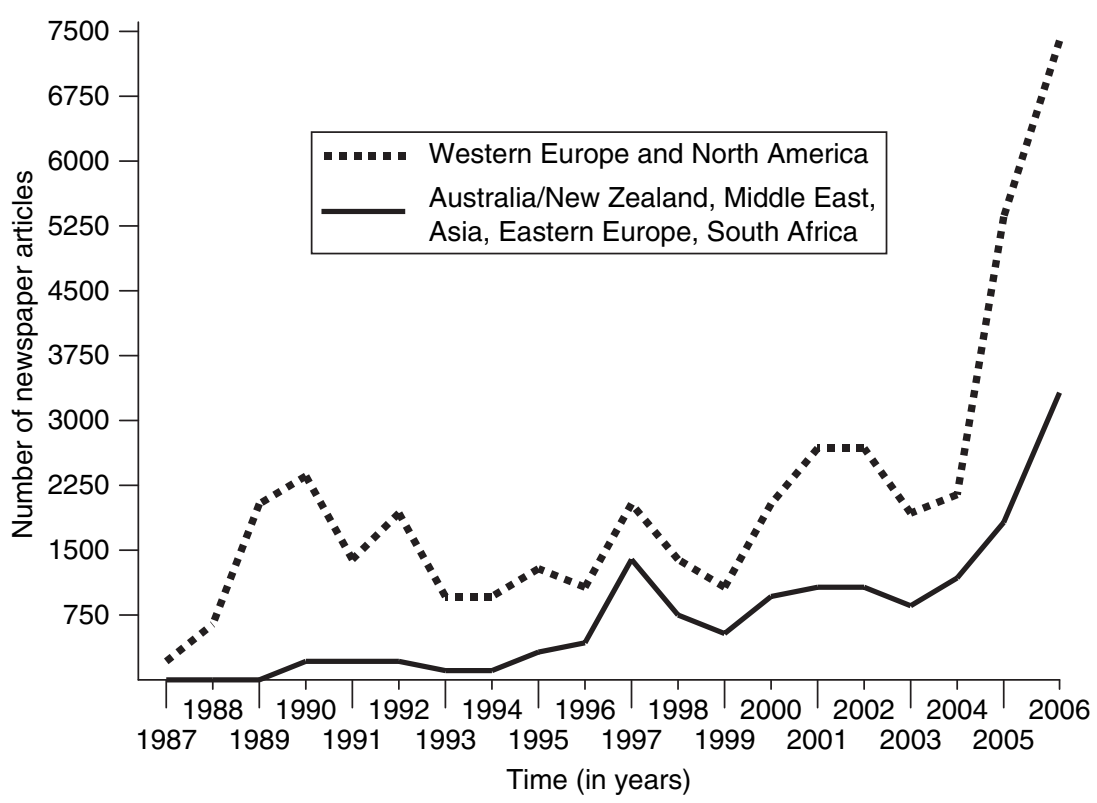

Fig. 1. Newspaper coverage of climate change or global warming. This notes the increases in quantity of coverage of climate change or global warming over time. The newspapers covered were the Sydney Morning Herald, The Age (Melbourne), the Courier-Mail (Brisbane), The Australian, the Daily Telegraph (Sydney), Globe and Mail (Toronto), the Toronto Star, the South China Morning Post (Hong Kong), the Prague Post, the Irish Times (Dublin), the Jerusalem Post, the Jerusalem Report, Yomiuri Shimbun (Tokyo), the Japan Times (Tokyo), Mainichi Shimbun (Tokyo), the Korea Herald, the Korea Times (Seoul), the New Straits Times (Wilayah Persekutuan), Het Financieele Dagblad (Eindhoven), the New Zealand Herald (Auckland), the Dominion Post (Wellington), The Press (Christchurch), the Moscow News, the Moscow Times, The Straits Times (Singapore), Business Day (Johannesburg), the Financial Mail (Johannesburg), the Sunday Times (Johannesburg), The Nation (Bangkok), The Guardian (London), the Observer (London), The Independent (and The Independent on Sunday) (London), The Times (and Sunday Times) (London), the Financial Times (London), The Herald (Glasgow), The Scotsman (and Scotland on Sunday) (Edinburgh), the Los Angeles Times, The New York Times, U.S.A. Today (McLean, VA), the Wall Street Journal (New York) and The Washington Post.

2005 in the Gulf Coast of the USA, garnered considerable media coverage, as the event tapped into many related issues of risk, hazards and vulnerability, as well as questions regarding what the causes were, who was responsible, and what needed to be done. In 2006, the release of the influential film An Inconvenient Truth with Al Gore, and the media coverage of the UK 'Stern Review' on the economic costs of climate-change mitigation, impacts and adaptation further spurred media coverage across the world.

Shifting attention more centrally to the factors shaping the content of news reports, influences are complex, non-linear and dynamic. Although climate-change science, policy and ecologicalmeteorological events have shaped media reporting and public understanding, journalism and public concern have also shaped climate science and policy decisions. Within the mass media, a number of intersecting political, economic, cultural, social and journalistic factors shape what is seen as the news or Internet article and television or radio segment.

Mass-media editors and reporters must navigate through many pressures and challenges while reporting the news. These are very difficult to disentangle, as factors interact and feed back through time, as well as re-embed themselves in macrorelations (such as decision-making within the capitalist political economy) and micro-processes (such as everyday journalistic practices). For instance, micro-level journalistic decisions are made in the context of macro-level pressures, where journalist's constraints on time-to-deadlines and space exist within a predominantly corporate-controlled media environment (Bagdikian 2004). This can unavoidably limit the depth of reporting, by editors and journalists, and this situation can be particularly troubling when covering a complex issue such as climate-change science and policy (Weingart et al. 2000). Research has documented that deadlines and space considerations constrain 
journalists (Schudson 1978), and editorial preferences and publisher pressures can affect news reporting (Schoenfeld et al. 1979). Moreover, the amount of exposure and placement (front page or buried deep in the newspaper), as well as the use of headlines and photographs, which are often editorial decisions, can also affect how events and situations are construed by the public.

Although many of these multifarious pressures and norms are codified and explicit, others are implicit, and shaped by social convention. Factors such as access and power to affect public discourse through ownership and media control are more readily apparent, whereas other influences, such as a journalist's background and training, are more concealed. Economic considerations have led to decreased mass-media budgets for investigative journalism (McChesney 1999), and have led to more journalists working as 'generalists' by covering many areas of news, rather than 'specialists' on a particular news beat (Gans 2004). In climate science and policy reporting, generalists are at a distinct disadvantage in terms of detailed scientific knowledge. A lack of science training among journalists can serve as a detriment to translations of climate-change science and policy information (McComas \& Shanahan 1999; Wilson 2000). Moreover, in the case of climate change, the biophysical agency of the environment is centrally important, as dramatic environmental events such as the breaking off of a large piece of the disintegrating Larson B ice shelf in 2003 can affect media coverage of that and other related climate-change issues. Above all, these multiple pressures shape and affect the continuing process of media production.

A key function of mass-media coverage of environmental issues has been to 'frame' them for policy actors and the public. Generally, framing is employed to contextualize and organize the dynamic swirl of issues, events and occurrences. It can be defined as the ways in which elements of discourse are assembled that then privilege certain interpretations and understandings over others (Goffman 1974). Media framing involves an inevitable series of choices to cover certain events within a larger current of dynamic activities. Through journalistic norms and values, certain events become news stories, thereby shaping public perception (Tuchman 1978; Iyengar 1991). According to Entman, 'Framing essentially involves selection and salience' and it 'plays a major role in the exertion of political power, and the frame in a news text is really the imprint of power-it registers the identity of actors or interest that competed to dominate the text' (Entman 1993, pp. 52-55). Asymmetrical influences also feed back into these social relationships and further shape emergent frames of 'news', knowledge and discourse.
Overall, various actors, both individuals and collective, seek to access and utilize mass-media sources to shape perceptions of environmental issues contingent on their perspectives and interests (Nisbet \& Mooney 2007). Earlier work in media studies of the environment has looked at the increasing attention paid to environmental issues through varying roles of 'interest group entrepreneurs', or claims-makers in constructing environmental issues as social problems (Schoenfeld et al. 1979). Mass media represent a key arena where such claims are communicated as well as contested and negotiated. In this mix of pressures and influences, a particular challenge to media coverage of climate-change science and policy, along with many associated factors, gains salience and thus warrants further discussion: dealing appropriately with uncertainty.

\section{Communicating (climate) uncertainty through mass media}

Uncertainty is not inherent only to scientific inquiry; it also appears in places such as business, marketing, and insurance endeavours, informing, yet not prohibiting action. Inquiry contains uncertainty by definition, as it operates past the bounds of certainty in examinations, critiques and analyses of the unknown. Translated by mass media at the science-policy interface, uncertainty often garners a great deal of attention, and is a battlefield for meaning. In past research, uncertainty has been explored more generally in relation to media coverage (Boffey et al. 1999; Dunwoody 1999; Gee 2000).

Some observers regard strategic insertions of uncertainty in anthropogenic climate-change discourse in science, as well as in the media, as a tactic deployed by intransigent policy actors to invalidate the overall public concern for global warming as an environmental-social problem' (Williams 2000, p. 70). In this more deliberate and often nefarious form, uncertainty can be reframed as scientific incompetence. In the case of climate change, oppositions have arisen primarily in a cohesive group of 'climate contrarians', dubbed 'climate sceptics' or the 'carbon club', who have gained significant discursive traction through the media, and, as a result, have significantly affected public understanding. In terms of environmental issues more broadly, Freudenberg has discussed constructions of "nonproblematicity'. Through embedded power and leveraged legitimacy, 'if one person or social group is able to obtain privileged access to valued resources without having other persons or groups challenge that privilege-or perhaps even notice 
it—so much the better' (Freudenburg 2000, p. 106). Research by McCright \& Dunlap has focused on this opposition movement, and has examined how climate contrarians have developed competing discourses that challenge top climate scientific evidence, and effectively gain a foothold in national and international discourse on the causes of climate change (McCright \& Dunlap 2000). These researchers also examined links between contrarians and conservative think tanks, anti-environment movements and carbon-based industry (McCright \& Dunlap 2003). Climate contrarians include scientists S. Fred Singer, Robert Balling, Sallie Baliunas, David Legates, Sherwood Idso, Frederick Seitz, Richard Lindzen and Patrick Michaels.

Contrarian voices, although heterogeneous in some ways, have garnered media coverage and have thus amplified uncertainty regarding various aspects of climate science, from questions of anthropogenic climate change to validity of modelling research. Research has revealed that scientific uncertainty has been a key ingredient inserted into discourse, to raise the perception of debate (Wilkins 1993; Zehr 2000). This perception of debate has often been seized upon by policy actors to justify resistance to various climate policy approaches. Policy-makers such as James Inhofe and Chuck Hagel have received extensive media coverage for their contrarian comments on climate change. Inhofe (Republican, Oklahoma), former Chair of the Senate Environment and Public Works committee, has said, 'could it be that man-made global warming is the greatest hoax ever perpetrated on the American people? It sure sounds like it' (Inhofe 2003). Senator Chuck Hagel (Republican, Nebraska) has said, 'The scientific community has simply not yet resolved the question of whether we have a problem with global warming. They have not been able to definitively conclude if the warming that has occurred in this century is due to human action or natural variations in the earth's atmosphere' (Hagel 1997).

In the summer of 1998, the Nebraska newspaper Omaha World Herald posed the question, 'What do Ginger Spice, Chuck Hagel and global warming have in common?' Part of the answer was that Hagel had recently held up the 'Oregon Petition', assembled by Frederick Seitz and signed by 17000 'scientists', on the US Senate Floor. This petition questioned scientific evidence that greenhouse gases cause global warming, and stated that the USA should pull out of international climate agreement negotiations. The other part of the answer was that a number of the names listed on the petition were not actually scientists, and some were not even real people. The list included people such as Ginger Spice of the Spice Girls, listed as 'Dr. Gerri Halliwell' as well as characters from the popular US television show MASH (Johansen 2002). None the less, this 'scientist's petition' has recirculated many times in opinion or editorial columns, interviews and commentaries in subsequent years through mass-media channels. For instance, religious leader Pat Robertson held up this petition in February 2006 on the $700 \mathrm{Club}$ program to undercut the authority of the IPCC as a 'radical environmental group that want to shut America down ... [and] that have an agenda that is far beyond just helping the environment' (Robertson 2006). One can dismiss this banter as nonsense, but the discursive sway that such assertions have over their viewers warrants attention.

Organizational entities have also used aspects of uncertainty to stage disinformation campaigns via the media. Moreover, the media have at times served as a watchdog rather than a conduit for such activities, despite deliberate efforts to the contrary. Prominently illustrating both these points is the 1998 leak of a draft of an industry proposal that was developed by carbon-based industry. The New York Times revealed that opponents of mandatory international action regarding climate change, such as the Kyoto Protocol, put together a plan with a $\$ 600000$ budget to recruit scientists 'who share the industry's views of climate science and to train them in public relations so they can help convince journalists, politicians and the public that the risk of global warming is too uncertain to justify'. This plan was to be directed at science writers, editors, columnists and television network correspondents, and was to raise questions about and undercut the 'prevailing scientific wisdom'. Moreover, the leaked proposal stated that it would measure success 'by counting, among other things, the percentage of news articles that raise questions about climate science and the number of radio talk show appearances by scientists questioning the prevailing views'. This campaign was reportedly crafted and assembled at American Petroleum Institute offices in Washington, DC by a range of interests from major oil companies, conservative policy research organizations and trade associations (Cushman 1998, p. A1).

In 2003, a memo from US Republican strategist Frank Luntz was leaked to the press (e.g. Burkeman 2003). This memo focused on 'winning the global warming debate' and emphasized key messages that Republicans should convey to the public via mass media. Among them, the memo outlined: 'Voters believe there is no consensus about global warming within the scientific community... Therefore, you need to continue to make the lack of scientific certainty a primary issue in the debate ... the scientific debate is closing (against us) but not yet closed. There is still a window of 
opportunity to challenge the science' (Luntz 2003, p. 142, italics in original).

Another example of policy and carbon-based industry relations' attempt to highlight uncertainties in climate science was reported through the mass media in 2005. Documents regarding the US Climate Science Program drafts in 2002 and 2003 were leaked to the press. These showed that White House Council on Environmental Quality (CEQ) Chief of Staff Phillip Cooney made edits to these documents, after they had undergone multiple drafts of peer review from experts in climate science, to weaken stated links between greenhouse gas emissions and climate change. Of note, Cooney had worked as a lobbyist for the American Petroleum Institute on climate issues before his time at the CEQ (Revkin 2005a). Cooney, who has no background in science, made subtle changes to wording and tone in many passages in the draft, and thus raised uncertainty and debate in aspects of the climate research that scientists working on the project found relatively certain, including that of anthropogenic climate change. For instance, Cooney inserted the words 'significant and fundamental' before the word 'uncertainties' in the document, thereby changing the communicated meaning (Revkin 2005a). Two days after these edits were leaked, Cooney resigned from the CEQ. Three days after that, it was announced that Cooney was hired as a consultant for ExxonMobil (Revkin 2005b).

Overall, these examples demonstrate the multifarious challenges faced when translating scientific uncertainty via mass media. Focusing on communications from scientists, it is often very difficult to place the uncertainty associated with one's research into a familiar context, through an appropriate analogy; in other words, 'translating error bars into ordinary language' (Pollack 2003, p. 77). Frankly, it is unavoidably challenging to accurately distil years of iterative research into media-friendly sound bites. As a result, most scientists need not look far, to colleagues or a mirror, to realize that climate scientists have often shied away from media interactions, thus leaving sourcing for stories to other communities for interpretation. When subject to interpretation primarily from policy actors, and interest groups (from nongovernmental organizations to carbon-based industry spokespeople), there are risks that inaccurate amplification or diminution of uncertainty can obfuscate or confuse rather than clarify many important aspects of the subject. In other words, the 'battlefield' of communicating and understanding environmental geoscience is not well served by scientists reluctant to acknowledge and act on what is an integral piece of one's contemporary responsibility: interacting with mass media.

\section{Conclusion}

The focus on media and science communication of climate change, arguably the most heavily politicized scientific issue at the turn of the new millennium, provides a number of opportunities. Among them, examinations of these amplified interactions can inform and anticipate other current science issues, such as continuing concerns for toxic materials or genetically modified organisms in the environment, nanotechnological risks, and increased threats to water quality. By unpacking and analysing interactions that focus on climate science and media interactions, representative challenges ranging from extrinsic issues (e.g. political economics) to intrinsic issues (e.g. uncertainty) can inform perceptions and decision-making.

Although this case-study has focused on the challenges in science and mass-media interactions, there are also a number of opportunities for improvements. With a focus on science and media communities in this case of climate change, these opportunities also apply across other arenas of science. Beginning with the scientific community, there are many more opportunities to develop skills to more effectively work with the media. In past decades, it is well known that most reward systems within science (and academia more broadly) were structured such that little was gained professionally through increased 'nonacademic' pursuits, such as media outreach (Boykoff 2007a). In fact, the opposite was true, as much could be lost, such as time spent in these endeavours. It was also widely sensed that much could be risked if one were misquoted about the implications of their research. Such impediments contributed to troubled interactions between science and media communities.

However, some argue that the situation is changing and that increased visibility through media coverage has increased public understanding of and engagement with scientific issues, increased collegial or social status, and even enhanced funding possibilities for researchers and scholars. These last benefits also hold for the university where they may be employed, thus providing a new and positive feedback loop. Although media outreach may continue to be ranked routinely below many other pressures (such as grant funding and publishing) the increasing recognition of its importance has proven to be an encouraging sign for effective communication of environmental geoscience via mass media. In addition, there are now more workshops and conferences that bring together scientists to discuss these issues (e.g. the Aldo Leopold Leadership Program) and others that bring together scientists and journalists (e.g. US National Science Foundation-funded projects). 
These opportunities for discussion and critical reflection or diffraction bode well for more consistent and improved communications into the future.

In terms of media communities on the larger scale, there have been many movements in recent years for broader reforms of journalistic freedom (e.g. McChesney 1999) within the constructs of corporate media pressures (outlined above). In addition, there have been vibrant independent media movements to circumvent some of the political economic pressures of corporate control. There has also been evidence of improvements on the individual level in terms of better contextualization of the complexities of the scientific issues covered, and more precise and accurate descriptions of those quoted within stories (Boykoff 2007b). Previous research has found that situating controversial information in the larger context of the scientific issue has helped to mitigate perceived uncertainty and confusion (Corbett \& Durfee 2004). In terms of the latter, The New York Times environment reporter Andrew Revkin has described this improvement as better capturing 'truth' through labelling. Although scientific research and scientific consensus are not 'truths' necessarily, they signify aspects of science where there is clear understanding.

Overall, this paper has sought to complement others in this volume by first delineating various challenges faced in interactions between science and mass media, and then briefly outlining some opportunities for more focused communications of environmental geoscience. By describing some of the multifarious pressures that shape interactions between climate science and mass media, this essay endeavours to more clearly identify key points of resistance and possibility as we collectively proceed with caution. Returning to McPhee, he has written, '[T]he human mind may not have evolved enough to be able to comprehend deep time' (McPhee 1998). In other words, human understanding of long-term geological time scales remains a core challenge. Thus, there are many thorny difficulties that make this endeavour a tricky one overall. However, this is the necessary task at hand in communicating environmental geoscience in the future.

\section{References}

Bagdikinn, B. 2004. The Media Monopoly. Beacon Press, Boston, MA.

Boffey, P. M., Rodgers, J. E. \& Schneider, S. H. 1999. Interpreting uncertainty: a panel discussion. In: Friedman, S. M., Dunwoody, S. \& Rogers, C. L. (eds) Communicating Uncertainty: Media Coverage of New and Controversial Science. Lawrence Erlbaum, Mahwah, NJ, 81-94.
BORD, R. J., O'CONNOR, R. E. \& Fischer, A. 2000. In what sense does the public need to understand global climate change? Public Understanding of Science, 9, 205-218.

BOY KOFF, M. T. 2007a. From convergence to contention: United States mass media representations of anthropogenic climate science. Transactions of the Institute of British Geographers, 32, 477-489.

BoYkofF, M. T. 2007b. Flogging a dead norm? Media coverage of anthropogenic climate change in the United States and United Kingdom from 2003-2006. Area, 39, 470-481.

Briggs, A. \& Burke, P. 2005. A Social History of the Media: from Gutenberg to the Internet. Polity Press, Cambridge.

Burkeman, O. 2003. Memo exposes Bush's new green strategy. The Guardian, 4 March, 1.

Corbett, J. B. \& Durfee, J. L. 2004. Testing public (un)certainty of science: media representations of global warming. Science Communication, 262, 129.

Cushman, J. H. 1998. Industrial group plans to battle climate treaty. The New York Times, 26 April, A1.

Dunwoody, S. 1999. Scientists, journalists, and the meaning of uncertainty. In: FRIEDMAN, S. M., Dunwoody, S. \& Rogers, C. L. (eds) Communicating Uncertainty: Media Coverage of New and Controversial Science. Lawrence Erlbaum, Mahwah, NJ, 59-80.

Entman, R. M. 1993. Framing: toward clarification of a fractured paradigm. Journal of Communication, 434, $51-58$

FreudenburG, W. R. 2000. Social construction and social constrictions: toward analyzing the social construction of 'the naturalized' and well as 'the natural'. In: SpAargaren, G. Mol, A. P. J. \& ButTel, F. H. (eds) Environment and Global Modernity. Sage, London, 103-119.

Gans, H. 2004. Deciding What's News. Northwestern University Press, Evanston, IL.

GEE, D. 2000. Communicating complexity and uncertainty: a challenge for the media. In: SMITH, J. (ed.) The Daily Globe: Environmental Change, the Public and the Media. Earthscan, London, 208-222.

Goffman, E. 1974. Frame Analysis: An Essay on the Organization of Experience. Harvard University Press, Cambridge, MA.

Gupta, J. 2001. Our Simmering Planet: What to Do About Global Warming? Zed Books, New York.

HAGEL, C. 1997. Countdown to Kyoto: the consequences of mandatory global $\mathrm{CO}_{2}$ emission reductions, Canberra. World Wide Web Address: wwww.corpwatch.org/ trac/corner/worldnews/other/355.html.

InHOFE, J. 2003. The science of climate change Senate Floor statement. US Senate, Committee on Environment and Public Works, 28 July.

IYENGAR, S. 1991. Is Anyone Responsible? University of Chicago Press, Chicago, IL.

Johansen, B. E. 2002. The Global Warming Desk Reference. Greenwood Press, Westport, CT.

Leggett, J. K. 2001. The Carbon War: Global Warming and the End of the Oil Era. Routledge, New York.

LuntZ, F. 2003. The Environment: A Cleaner, Safer, Healthier America. The Luntz Research CompaniesStraight Talk, Washington, DC, 131-146. 
MCChesney, R. W. 1999. Rich Media, Poor Democracy: Communication Politics in Dubious Times. University of Illinois Press, Urbana, IL.

McComas, K. \& Shanahan, J. 1999. Telling stories about global climate change: measuring the impact of narratives on issue cycles. Communication Research, 261, 30-57.

MCCRight, A. M. \& Dunlap, R. E. 2000. Challenging global warming as a social problem: an analysis of the conservative movement's counter-claims. Social Problems, 474, 499-522.

MCCRight, A. M. \& Dunlap, R. E. 2003. Defeating Kyoto: the conservative movement's impact on US climate change policy. Social Problems, 503, 348-373.

MCPhee, J. 1998. Annals of the Former World. Farrar Straus Giroux, London.

Nelkin, D. 1987. Selling Science: How the Press Covers Science and Technology. W. H. Freeman, New York.

Nisbet, M. C. \& Mooney, C. 2007. Framing science. Science, 3166, 56.

Peterson, C. 1989. Experts, OMB spar on global warming: 'greenhouse effect' may be accelerating, scientists tell hearing. The Washington Post, 9 May, A1.

Pollack, H. 2003. Can the media help science? Skeptic, 102, 73-80.

REVKIn, A. 2005a. Bush aide edited climate reports. The New York Times, 8 June, A1.

REVKIN, A. 2005b. Former Bush aide who edited reports is hired by Exxon. The New York Times, 15 June, A21.
Robertson, P. 2006. Evangelism and environment. 700 $C l u b, 9$ February.

Schoenfeld, A. C., Meier, R. F. \& Griffin, R. J. 1979. Constructing a social problem: the press and the environment. Social Problems, 271, 38-61.

Schudson, M. 1978. Discovering the News: A Social History of American Newspapers. Basic Books, New York.

SHABECOFF, P. 1988. Global warming has begun, expert tells Senate. The New York Times, 24 June, A1.

Tuchman, G. 1978. Making News: A Study in the Construction of Reality. Free Press, New York.

Weingart, P., Engels, A. \& Pansegrau, P. 2000. Risks of communication: discourses on climate change in science, politics, and the mass media. Public Understanding of Science, 9, 261-283.

WiLKINS, L. 1993. Between the facts and values: print media coverage of the greenhouse effect, 19871990. Public Understanding of Science, 2, 71-84.

WiLliams, J. 2000. The phenomenology of global warming: the role of proposed solutions as competitive factors in the public arenas of discourse. Human Ecology Review, 72, 63-72.

Wilson, K. M. 2000. Communicating climate change through the media: predictions, politics, and perceptions of risk. In: Allan, S., ADAM, B. \& CARTER, C. (eds) Environmental Risks and the Media. Routledge, London, 201-217.

ZEHR, S. C. 2000. Public representations of scientific uncertainty about global climate change. Public Understanding of Science, 9, 85-103. 